Acta Cryst. (2002). A58 (Supplement), C211

\section{SUPRAMOLECULAR ORGANIZATION IN RUTHENIUM}

\section{COMPLEXES}

J.. Ellena $^{1}$ M. B. Ribeiro ${ }^{1}$ A. A. Batista ${ }^{2}$ J. R. Sousa ${ }^{2}$ K. Wonhrath ${ }^{2}$ L. R. Dinelli $^{2}$ E. E. Castellano ${ }^{1}$

${ }^{1}$ Instituto de Fisica de Sao Carlos - Universidade de Sao Paulo, Sao Carlos (SP) - Brazil - CEP 13.560-970 - C.P. $36^{2}$ Departamento de Quimica, Universidade Federal de Sao Carlos, Sao Carlos (SP) - Brazil - CEP 13.565-905 - C.P. 67

$\mathrm{Ru}(\mathrm{II})$ complexes containing a single bis(diphenylphosphine) ligand per metal center are of interest because of their role in catalytic hydrogenation reactions[1]. The supramolecular organization of these compounds has shown to be very significant. At the same time these complexes have been used to form supramolecular porphyrin species with exceptionally large electrocatalytic activities [2-3]. One of the most exciting recent developments in inorganic porphyrin chemistry has been the elaboration of modified electrode assemblies in which the supramolecular organizations have shown to be very important and probably responsible for many of the electrochemical properties of these systems. Here we present a study of the solid-state supramolecular organization of some $\mathrm{Ru}$ complexes of the type $\mathrm{RuCl}_{3}(\mathrm{dppb}) \mathrm{L}$, were dppb is the 1,4-bis(diphenyl phosphine)butane and $\mathrm{L}$ is a N-heterocyclic ligand like 4,4'-bipyridil and pyridine. The $\mathrm{RuCl}_{3}(\mathrm{dppb})$ pyridine complex was also used as start material to form the tetraruthenate porphyrin $\{\mathrm{Ni}(\mathrm{II})$ TPyP $\left.\left[\mathrm{RuCl}_{3}(\mathrm{dppb})\right]_{4}\right\}$ in which the supramolecular forces add to the formation of a thin film by an electrochemical cyclic deposit procedure in the electrode surface. The comparison of the crystallographic results with the spectroscopic (EPR) data in solid state and in solution help to enlighten the nature of the supramolecular interactions present in these species.

References

[1] James B.R., McMillan R.S., Morris R.H. \& Wang D.K.W. (1978) Adv. Chem. Ser 167, 127.

[2] Shi C.N. \& Anson, F.C. (1992) Inorg. Chem. 31, 5078.

[3] Anson F.C., Shi. C.N. \& Steiger B. (1997) Acc Chem. Res., 30, 437.

\section{Keywords: RUTHENIUM COMPLEXES SUPRAMOLECULAR ASSEMBLIES PORPHYRINES}

Acta Cryst. (2002). A58 (Supplement), C211

PRESENT AND FUTURE HIGH BRILLIANCE X-RAY SOURCES Th. Tschentscher

HASYLAB at DESY, Notkestrasse 85, 22603 Hamburg, Germany

Accelerator-based $\mathrm{x}$-ray sources have seen in recent years a strong increase of the x-ray beam brilliance. One presently observes at storage rings of the latest generation an average brilliance of several $10^{20} \mathrm{phts} / \mathrm{s} / 0.1 \% \mathrm{bw} / \mathrm{mm}^{2} / \mathrm{mrad}^{2}$ for a wide range of photon energies. This brilliance has enabled several new applications of $x$-ray scattering, like e.g. scattering experiments using coherent $\mathrm{x}$-rays and micro-focusing. A further increase in brilliance of two orders of magnitude seems feasible for an ultimate storage design. Increasing the brilliance by further orders of magnitude will require new accelerator concepts. Recently two different concepts have been proposed. First, energy recovery linear accelerators (ERL) make use of single turns of an electron bunch in the ring-like accelerator, thus preserving its emittance and duration. ERLs will raise significantly the peak brilliance, which takes account of the pulse duration. Second, free-electron lasers (FEL) using the self-amplified spontaneous emission principle will allow to combine pulse durations of the order 100 femtoseconds with high photon number per pulse. FELs would increase the average brilliance by up to four orders of magnitude and the peak brilliance by roughly ten orders of magnitude, compared to existing synchrotron radiation sources. These new sources will open possibilities for new scientific applications in many scientific domains and will in the same time define very severe requirements to $\mathrm{x}$-ray optics. In comparison to accelerator-based concepts table-top laser driven x-ray sources are mostly limited in their accessible wavelength regime. Peak brilliances several orders higher than present-day synchrotrons have been observed already.

Keywords: X-RAY SOURCES, BRILLIANCE, COHERENCE

Acta Cryst. (2002). A58 (Supplement), C211

\title{
CAPILLARY OPTICS IN X-RAY DIFFRACTOMETRY OF CRYSTALS
}

M.A. Kumakhov ${ }^{1}$ E.K. Koviev ${ }^{2}$ M.S. Akchurin ${ }^{3}$ S.N. Polyakov ${ }^{4}$ Institute for Roentgen Optics 1st Volokolamsky Pr. 10, PMZR MOSCOW 123060 RUSSIA

Current extensive development of X-ray poly-capillary optics allows defining it as a separate field of investigation widely used in a wide range of X-ray studies. For diffractometry, the most interesting are poly-capillary half-lenses having a small-size focal spot with large capture angle at the inlet and producing an intensive quasi-parallel X-ray beam at the exit. These features enable their use in different methods of crystalline matter analysis.

This paper presents a new version of diffractometry method developed based on poly-capillary half-lenses for absolute inter-planar spacing measurements in crystals with accuracy of $(\Delta \mathrm{d} / \mathrm{d})_{\mathrm{hk}}$ less or equal to $10^{-5}$. In X-ray diffractometry, poly-capillary half-lenses can be successfully used as monochromators featuring high angular and energy resolution to form primary X-ray beam. For quartz crystals with (50-52)-reflection, the resolution of $\Delta \mathrm{E}$ approximately equal to15 eV has been achieved. Application of poly-capillary half-lenses in $\mathrm{X}$-ray absorption spectrometry is also discussed.

Poly-capillary half-lenses together with vacuum collimator permits the transmission without any significant losses of $\mathrm{X}$-ray monochromated radiation over long distances $(2-4 \mathrm{~m})$.

\section{Keywords: CAPILLARY OPTICS APPLICATION}

Acta Cryst. (2002). A58 (Supplement), C211

\section{X-RAY MICROFOCUSING: TECHNIQUES AND APPLICATIONS} A Snigirev

ESRF, BP 220, 6 Rue Jules Horowitz GRENOBLE 38043 FRANCE

The small source size and low divergence of third generation synchrotron radiation sources give rise to tremendous advances in the development of different types of focusing optics based on reflection, diffraction and refraction phenomena. The presentation is intended to review the most resent developments of hard X-ray optics with main emphasis on the performances of micro- and nanofocusing devices such as Kirkpatrick-Baez systems, Fresnel zone plates, compound refractive lenses, waveguides and capillary optics. Some of the possible advantages and limitations of these devices for undulator and bending magnet beamlines are presented. Several illustrative examples of applications specific to each technique such as microdiffraction, microspectroscopy, microimaging and microtomography are given. The presentation concludes with a look at future prospects, including the optics development for new X-ray free-electron lasers.

\section{Keywords: X-RAY OPTICS, MICROFOCUSING, SYNCHROTRON RADIATION}

